\title{
Measuring Contagion of Subprime Crisis Based on MVMQ-CAViaR Method
}

\author{
Wuyi Ye, Kebing Luo, and Shaofu Du \\ School of Management, University of Science and Technology of China, Hefei 230026, China \\ Correspondence should be addressed to Shaofu Du; dsoft@ustc.edu.cn
}

Received 13 March 2014; Accepted 8 May 2014; Published 9 June 2014

Academic Editor: Fenghua Wen

Copyright (C) 2014 Wuyi Ye et al. This is an open access article distributed under the Creative Commons Attribution License, which permits unrestricted use, distribution, and reproduction in any medium, provided the original work is properly cited.

\begin{abstract}
The analysis of financial contagion is a topical issue in international finance and portfolio management. In this paper, we investigate whether the global financial crisis originating from American subprime crisis spreads to China, Japan, UK, France, and Germany. Firstly, multivariate conditional autoregressive value at risk (MV-CAViaR) models are applied to the whole sample to analyze the variation of market risk among these countries. By dividing the sampling period into three important subperiods (precrisis period, crisis period, and recovery period), we examine the changes of the dependence structure of risk during each period. Comparing with the situations in precrisis period, if the estimated coefficients become significant or market risk increases during the crisis, it implies the existence of contagion from the angle of coefficient significance or risk. The findings show that the concerned coefficients are significant or the market risks of the tested countries increase during the crisis except for China. The results imply that there is contagion from the US to all other countries, except for China. Furthermore, the changes of the market risk are found to be consistent with market events and media reports during that period.
\end{abstract}

\section{Introduction}

An observation that stock markets behave very similarly across different continents and countries during the global financial crisis of 2008-2009 casts serious doubts on the question whether financial contagion exists and, if so, to what extent markets covary during the turmoil. The financial contagion has vital impacts on the performance of international portfolios and risk management. Investors are interested in international diversification of risks. But, if the financial markets are more closely linked during the crisis, the opportunities for international diversification are decreased. For regulators of financial markets, it is particularly important to comprehend such linkage increase among world financial markets. As a result, the topic issue has attracted a considerable amount of interest among academic researchers.

One may wonder about the existence of a contagion phenomenon across different financial markets worldwide. For this purpose, it is necessary to define the concept of contagion, despite the fact that several advanced results remain hard and complex to identify contagion. In this paper, we draw lessons from the definition of contagion introduced by Forbes and Rigobon [1], who defined it as a significant increase in the market comovement after a shock happened in a country. It suggests that the financial contagion does not occur if two markets show a high degree of comovement during both tranquil and turbulent phases. In this paper, we say that there exists financial contagion only if one of the two following conditions is satisfied. (i) The interested coefficients are statistically significant during the crisis but remain insignificant during the precrisis period. (ii) The interested coefficients are significant during both precrisis period and the crisis, but compared with precrisis period, the market risk increases during the crisis.

The literature, which focuses on changes of financial market dependence in a crisis period against a tranquil period, has grown substantially in recent years and is generally related to the terminology "contagion." Baig and Goldfajn [2] and Forbes and Rigobon [1] use a linear dependence measure. Bae et al. [3] apply a multinomial logit model to estimate coexceedances. Baur [4] proposes an alternative quantile regression framework to decompose the dependence into the degree and structure of dependence. But, the estimated quantile is static and not dynamically varying with time at 
some given level. To detect the dynamic characteristics of financial contagion, following from Engle and Manganelli [5] and White et al. [6, 7], we use multivariate conditional autoregressive value at risk (MV-CAViaR) framework to estimate two dynamic conditional autoregressive quantile models simultaneously. We show that MV-CAViaR model provides a flexible modeling and estimation method to identify the financial contagion between two countries.

We contribute to the existing literature in two major ways. Firstly, compared with single quantile regression model, which can only study the contagious relation from one country to another, MV-CAViaR model can study the interactional contagion between two markets in dynamic settings from the angle of risk with the help of VaR. Moreover, considering the information of two countries simultaneously, we apply MV-CAViaR model to study financial contagion between the origin of global financial crisis (the US market) and major mature equity markets, namely, Japan, UK, France, Germany, and one of the biggest emerging markets (China). In this way, we can investigate not only the existence of contagion but also the changes of risk in two markets. In order to capture the variation of risk for the whole sampling period, MV-CAViaR models are employed to the overall sample between the US and other countries. We find that there is a high increase in value at risk for all sampling countries during the crisis period.

Secondly, our research accounts for the financial contagion and changes of risk by using a comprehensive time series spanning three periods: before, during, and after the crisis. In this way, we increase the efficiency of our estimation and enable a comparison of different phases by dividing the whole sample period into three periods (i.e., precrisis, crisis, and recovery periods). Then, we consider estimation of these models for three important subsamples, just as Mollick and Assefa [8] did. The first runs from January 2006 to December 2007 which is referred to as the precrisis period. The second, namely, the crisis period, starts at the beginning of 2008, right after NBER identified December of 2007 as the start of the major recent financial crisis in the US. (The National Bureau of Economic Research (NBER) is an American private nonprofit research organization "committed to undertaking and disseminating unbiased economic research among public policymakers, business professionals, and the academic community." The NBER is well known for providing start and end dates for recessions in the United States. NBER is the largest economics research organization in the United States. Many of the American winners of the Nobel Memorial Prize in Economic Sciences were NBER research associates. Many of the chairmen of the Council of Economic Advisers have also been NBER research associates, including the former NBER president and Harvard Professor, Martin Feldstein.) The US recession officially ended in June 2009, although economic growth has since been sluggish. The third subsample stretching from July 2009 to July 2013 refers to the US economy entering a recovery phase and we call it recovery period. By comparing the coefficient significance and the changes of risk during the three different phases, we judge whether there exists financial contagion from the US to the tested countries during the crisis and the economics enter the phase of recovery. The findings show that the American subprime crisis spread to Japan, UK, France, and Germany and increased their market risk during the crisis in contrast to precrisis period. But we have not found statistically significant evidence that there is financial contagion from America to China. During the recovery period, the comovement between the US and France exists, but from the perspective of risk the market risks in two countries become small in comparison with the risk in crisis period. For UK, there is no contagion phenomenon during the recovery period. However, there are risk spillovers from both Japan and Germany to the US due to market conditions of the day.

The rest of the paper is organized as follows. Section 2 provides the literature review about financial contagion. In Section 3, the multivariate multiquantiles CAViaR (MVMQCAViaR) framework and its estimation are detailed. Then, in Section 4, we perform empirical analysis to examine the possible financial contagion between the US and five tested countries. Finally, Section 5 concludes.

\section{Literature Review}

A rapid increase in global economic integration has accelerated financial integration, spillovers, and contagion in equity markets of different countries. Current studies on financial contagion offer many methods to measure the propagation of international shocks across countries. Investigating the financial transmission, Kaminsky et al. [9] categorize the theories into three groups: contagion caused by herding behavior (e.g., Banerjee [10], Calvo and Mendoza [11]); contagion resulting from trade linkages (e.g., Lahiri and Végh [12], Gerlach and Smets [13]); and contagion accelerated by financial links (e.g., Kodres and Pritsker [14], Fratzscher [15]). There are many approaches proposed to detect and identify the financial contagion. Next, we review the main approaches about the studies on financial contagion through financial linkages.

Early work on detecting contagion is obtained mainly by comparing the traditional constant Pearson correlation coefficient between two countries in times of relative calm with that in times of unusually high volatility (see, for instance, Reinhart and Calvo [16], Bordo and Murshid [17], and Forbes and Rigobon [18]). However, Corsetti et al. [19] show how these results are flawed in the presence of heteroscedasticity. The findings show that an increase in the variance of two variables will cause an increase in the correlation coefficient even if the propagation mechanism is unaltered. Moreover, Pearson correlation coefficient is a static linear correlation measure and cannot measure the nonlinear relation. Therefore, an increase in the correlation coefficient is not necessarily a proof of contagion. Rigobon [20] introduces the DCC test, which seems to provide a way to test parameter stability in the models with simultaneous heteroscedasticity and endogeneity problems. Recently, there are many literatures using DCC model to study financial contagion (see, e.g., Chiang et al. [21], Naoui et al. [22], Celik [23], and Dimitriou et al. [24]). In addition, there are numerous traditional econometric models to investigate the dependence or change of dependence. These include 
the volatility spillovers methods based on ARCH and GARCH models [25-27], extreme value theory (EVT) method [28], probit/logit models [29, 30], Markov switching model [31-33], the factor model [34], the copula approach [35-39], and wavelet analysis [40, 41]. But, none of these studies analyze the financial contagion from the angle of risk with the help of VaR directly.

More recently, quantile regression methods have gained popularity in economics and finance fields due to their appealing features in describing market risk directly. The quantile regression model was firstly proposed by Koenker and Bassett in 1978. Baur and Schulze [42] apply the quantile regression framework to examine the occurrences and degrees of coexceedances, concentrating on Hong Kong, Thailand, and Malaysia as the origin countries of the Asian crisis, and test the contagion effects on the US, Latin America, Europe, and other Asian countries. Chuang et al. [43] and Lee and $\mathrm{Li}$ [44] apply quantile regression to model the dependence of financial variables, for example, trading volume and return volatility. Engle and Manganelli [5] develop conditional autoregressive value at risk (CAViaR) model, a class of models suitable for estimating conditional quantile in dynamic settings. Engle and Manganelli apply the approach to estimate the market risk. White et al. [6] extend CAViaR model to permit joint modeling of multiple quantiles, that is, Multi-Quantile (MQ) CAViaR. They apply MQ-CAViaR model to estimate measures of conditional skewness and kurtosis defined in terms of conditional quantiles. Furthermore, White et al. [7] extend MQ-CAViaR model to a multivariate version of MQ-CAViaR model, called MVMQCAViaR model. The proposed framework can simultaneously accommodate models with multiple random variables, multiple confidence levels, and multiple lags of the associated quantiles. They estimated a simple version of the model using different market returns data and then constructed impulse response functions to study how financial institution specific and system wide shocks are absorbed by the system. In this paper, MV-CAViaR model is employed to research whether there was financial contagion from the US to the tested countries or not from the angle of the coefficients significance and the variation of risk before and after the American subprime crisis in dynamic settings. Moreover, by comparing the situation in the recovery period with that in the crisis, we explain how the tested countries affect American economic recovery. So far, we find there is no literature investigating the financial contagion with the model from the perspective of coefficient significance or risk.

\section{Methodology}

In this section, we firstly introduce MVMQ-CAViaR model following from White et al. [7]. The framework of the model can be conveniently thought of as a vector autoregressive extension to quantile models. Secondly, we present the asymmetric Laplace distribution (see Yu and Zhang [45] for details), which is the only distribution associated with quantile regression estimation. Then, we outline the quasimaximum likelihood method for estimating MVMQ-CAViaR model parameters.
3.1. MVMQ-CAViaR Model. It is assumed that $\left\{\left(Y_{t}^{\prime}, X_{t}^{\prime}\right): t=\right.$ $0, \pm 1, \pm 2, \ldots\}$ is stationary and ergodic stochastic process on the complete probability space $(\Omega, \mathscr{F}, P)$, where $Y_{t}$ is a finitely $n \times 1$ dimensioned vector and $X_{t}$ is a countably dimensioned vector whose first element is one.

$$
\begin{gathered}
\text { Let } \mathscr{F}_{t-1} \text { be the } \sigma \text {-algebra generated by } \\
\left\{\left(Y_{t-1}^{\prime}, X_{t-1}^{\prime}\right),\left(Y_{t-2}^{\prime}, X_{t-2}^{\prime}\right), \ldots\right\} \text {, that is, } \\
\mathscr{F}_{t-1} \equiv \sigma\left(\left\{\left(Y_{t-1}^{\prime}, X_{t-1}^{\prime}\right),\left(Y_{t-2}^{\prime}, X_{t-2}^{\prime}\right), \ldots\right\}\right) \text {. }
\end{gathered}
$$

For $i=1,2, \ldots, n$, define $F_{i, t}(y)=P\left(Y_{i, t}<y \mid \mathscr{F}_{t-1}\right)$ as the cumulative distribution function (CDF) of $Y_{i t}$ conditional on $\mathscr{F}_{t-1}$.

Let $\theta_{i, j}$ belong to $(0,1)$ for $i=1,2, \ldots, n ; j=1,2, \ldots, p_{i}$. The $\theta_{i, j}$ th quantile of $Y_{t}$ conditional on $\mathscr{F}_{t-1}$, denoted by $q_{i, j, t}$, is

$$
q_{i, j, t}=\inf \left\{y: F_{i, t}(y) \geq \theta_{i, j} \mid \mathscr{F}_{t-1}\right\} .
$$

For simplicity, we set $q_{t}=\left(q_{1, t}^{\prime}, q_{2, t}^{\prime}, \ldots, q_{n, t}^{\prime}\right)^{\prime}$ with $q_{i, t}=$ $\left(q_{i, 1, t}, q_{i, 2, t}, \ldots, q_{i, p_{i}, t}\right)^{\prime}$. For the given finite integers $m$ and $k$, there exist a stationary ergodic sequence of random $k \times$ 1 vectors $\left\{\Psi_{t}, t=1,2, \ldots, T\right\}$ with $\Psi_{t}$ measurable $\mathscr{F}_{t-1}$ and real vectors $\beta=c\left(\beta_{i, j, 1}, \beta_{i, j, 2}, \ldots, \beta_{i, j, k}\right)^{\prime}$ and $\gamma_{i, j, \tau}=$ $\left(\gamma_{i, j, \tau, 1}, \gamma_{i, j, \tau, 2}, \ldots, \gamma_{i, j, \tau, n}\right)$, where each $\gamma_{i, j, \tau, k}$ is $p_{i} \times 1$ vector, such that for $i=1,2, \ldots, n ; j=1,2, \ldots, p_{i}$ and all $t$,

$$
q_{i, j, t}=\Psi_{t}^{\prime} \beta_{i, j}+\sum_{\tau=1}^{m} q_{t-\tau}^{\prime} \gamma_{i, j, \tau} .
$$

The structure of (3) is a multivariate multiquantiles conditional autoregressive value at risk (MVMQ-CAViaR) model introduced by White et al. [7], itself a multivariate version of the MQ-CAViaR process of White et al. [6], which is a multiquantiles version of the CAViaR process proposed by Engle and Manganelli [5]. Under suitable restrictions on the $\gamma_{i, j, \tau}$, we get the following three situations as special cases: (1) univariate MQ-CAViaR process of each element of $Y_{t}$, (2) single quantile CAViaR process of each element of $Y_{t}$, and (3) multivariate CAViaR process in which a single quantile of each element of $Y_{t}$ is dynamically related to single quantiles of the other elements of $Y_{t}$ or lags of them.

It is worthwhile to note that, for MVMQ-CAViaR, the number of relevant lags can differ across the elements of $Y_{t}$ and conditional quantiles. In fact, it is possible that, for given $i$ and $j$, elements of $\gamma_{i, j, \tau}$ may be zero for the values of $\tau$ greater than a certain integer. For the simplicity of notation, $m$ is not denoted by $m(i, j)$. In addition, the finitely dimensioned random vectors $\Psi_{t}$ may include $Y_{t}$ or the lagged values of $Y_{t}$, as well as measurable functions of $X_{t}$ and lagged $X_{t}$. In special cases, $\Psi_{t}$ may contain Stinchcombe and White [46] GCR transformations, as discussed in White [47].

For the analytical convenience, in terms of a particular quantile, for example, $\theta_{i, j}$, the coefficients to be estimated are $\beta_{i, j}$ and $\gamma_{i, j}=\left(\gamma_{i, j, 1}^{\prime}, \gamma_{i, j, 2}^{\prime}, \ldots, \gamma_{i, j, m}^{\prime}\right)$. Let $\alpha_{i j}=\left(\beta_{i, j}^{\prime}, \gamma_{i, j}^{\prime}\right)$ and write $\alpha=\left(\alpha_{11}^{\prime}, \alpha_{12}^{\prime}, \ldots, \alpha_{1 p_{i}}^{\prime}, \ldots, \alpha_{n 1}^{\prime}, \alpha_{n 2}^{\prime}, \ldots, \alpha_{n p_{n}}^{\prime}\right)$, an $l \times 1$ vector, where $l=\sum_{i=1}^{n} p_{i}\left(k+n p_{i} m\right) . \alpha$ is called the MVMQCAViaR coefficient vector. 
To illustrate the usefulness of the models outlined above, we give an example specifying the model as follows:

$$
\begin{aligned}
& q_{1, t}=c_{1}+a_{11}\left|Y_{1, t-1}\right|+a_{12}\left|Y_{2, t-1}\right|+b_{11} q_{1, t-1}+b_{12} q_{2, t-1}, \\
& q_{2, t}=c_{2}+a_{21}\left|Y_{1, t-1}\right|+a_{22}\left|Y_{2, t-1}\right|+b_{21} q_{1, t-1}+b_{22} q_{2, t-1} .
\end{aligned}
$$

Since $P\left(Y_{i, t} \leq-\operatorname{VaR}_{i t} \mid \mathscr{F}_{t-1}\right)=\theta,-\operatorname{VaR}_{i t}$ is the $\theta$ th quantile of $Y_{i t}$ conditional on $\mathscr{F}_{t-1}$. Then, we get

$$
\begin{aligned}
\operatorname{VaR}_{1, t}= & c_{1}^{*}+a_{11}^{*}\left|Y_{1, t-1}\right|+a_{12}^{*}\left|Y_{2, t-1}\right| \\
& +b_{11} \operatorname{VaR}_{1, t-1}+b_{12} \operatorname{VaR}_{2, t-1}, \\
\operatorname{VaR}_{2, t}= & c_{2}^{*}+a_{21}^{*}\left|Y_{1, t-1}\right|+a_{22}^{*}\left|Y_{2, t-1}\right| \\
& +b_{21} \operatorname{VaR}_{1, t-1}+b_{22} \operatorname{VaR}_{2, t-1},
\end{aligned}
$$

where $c_{i}^{*}=-c_{i}, \alpha_{i j}^{*}=-\alpha_{i j}, i=1,2 ; j=1,2$.

Hence, the financial contagion can be detected from the perspective of the risk transmission. The financial contagion between the two financial markets is measured by the offdiagonal coefficients, $b_{12}$ and $b_{21}$, and the hypothesis of no contagion can be tested by testing $H_{0}: b_{12}=b_{21}=0$. The direction of the contagion can be captured by inspecting these two coefficients. For example, if $b_{12}=0$ and $b_{21} \neq 0$, then the direction of financial contagion is from country 1 to country 2 , not the other way around. At the same time, the degree of the contagion can be measured by the magnitude of $b_{12}$ and $b_{21}$. The larger $b_{12}$ or $b_{21}$ are, the more serious contagion between two markets is. In a similar way, the financial contagion can also be captured from the point of risk spillovers. We can investigate the existence of financial contagion by testing the significance of coefficients, $H_{0}: a_{12}^{*}=a_{21}^{*}=$ 0 . The directions of contagion can be determined from the hypothesis test, for example, $H_{0}: a_{12}^{*}=0$ and $a_{21}^{*} \neq 0$, which means there is contagion from country 1 to country 2 and no contagion from country 2 to county 1 . Similarly, the dependence structure can be analyzed from the sign and magnitude of the coefficients $a_{12}^{*}$ and $a_{21}^{*}$. The larger coefficients $a_{12}^{*}$ and $a_{21}^{*}$ are, the larger spillover risks are, which implies that the smaller coefficients $a_{12}$ and $a_{21}$ are, the larger spillover risks are.

3.2. The QMLE Estimate of MV-CAViaR Model. A possible parametric link between the minimization of the sum of absolute deviate for the estimation of quantile regression and the maximum theory is given by the asymmetric Laplace distribution. The asymmetric Laplace distribution presented here is only a kind of the asymmetric Laplace distributions. It is useful for fitting quantile or quantile regression as well as for data analysis in general; see Yu and Moyeed [48], Yu and Zhang [45] for details.

We say that a random variable $X$ is distributed as ALD with parameters $\mu, \sigma$, and $p$, denoted by $X \sim \operatorname{ALD}(\mu, \sigma, \tau)$, if it has the following probability density function (PDF):

$$
f(x ; \mu, \sigma, p)=\frac{p(1-p)}{\sigma} \exp \left\{-\frac{x-\mu}{\sigma}\left[p-I_{(x \leq \mu)}\right]\right\},
$$

where $-\infty<\mu<+\infty$ is the location parameter, $0<p<1$ is the skew parameter, $\sigma>0$ is the scale parameter, and $I_{(\cdot)}$ is the indication function, which takes the value one if the argument is true and zero otherwise.

Following from Koenker and Machado [49], we assume that the error terms in quantile regression are distributed as asymmetric Laplace distribution in this paper, that is, $Y_{i, t}-$ $q_{i, j, t} \sim \operatorname{ALD}\left(0, \sigma, \theta_{i j}\right)$. Then, we can estimate the unknown parameters by the method of quasimaximum likelihood. The likelihood function for $T$ independent observations is

$$
L\left(\alpha ; Y_{1}, Y_{2}\right) \propto \sigma^{-1} \exp \left\{\sum_{t=1}^{T} \sum_{i=1}^{n} \sum_{j=1}^{p_{i}} \frac{\rho_{\theta_{i j}\left(Y_{i, t}-q_{i, j, t}\right)}}{\sigma}\right\},
$$

where $\rho_{\theta}=e \Psi_{\theta}(e)$ is the standard check function (see Koenker and Basset [50]), defined by the usual quantile step function, $\Psi_{\theta}(e)=\theta-I_{(e \leq 0)}$. Because $Y_{i, t}-q_{i, j, t}$ are not necessarily distributed as this distribution, we call it quasimaximum likelihood estimator rather than maximum likelihood estimator as described in White et al. [7]. If we consider $\sigma$ as a nuisance parameter, the quasimaximum likelihood estimator $\widehat{\alpha}$ is equivalent to the solution to the following optimization problem:

$$
\widehat{\alpha}=\underset{\alpha \in \mathbb{R}}{\operatorname{argmin}} \sum_{t=1}^{T} \sum_{i=1}^{n} \sum_{j=1}^{p_{i}} \rho_{\theta_{i j}\left(Y_{i t}-q_{i, j, t}\right)} .
$$

Thus, ALD proves to be useful as unifying bridge between the likelihood and inference for QR estimation. For example, Koenker and Machado [49] introduced a goodness-of-fit process for QR and related inference process, and they also considered the likelihood ratio statistic under the parametric assumption of a Laplacean distribution for the error term. For Bayesian approach, see Yu and Moyeed [48], among others. The consistency and asymptotic normality for the estimated coefficients $\widehat{\alpha}$ are derived and detailed in White et al. [7]. Following this, we can get the significance test of coefficients.

\section{Data and Empirical Analysis}

4.1. Data. Our empirical study of 2008-2009 financial contagion focuses on equity market indices of six countries (S\&P 500 (US), CSI300 (China), Nikkei 225 (Japan), FTSE100 (UK), CAC-40 (France), and DAX (Germany)) from January 1, 2006, to July 25, 2013, which include the episode of the financial crisis of 2008-2009. We call China, Japan, UK, France, and Germany tested countries because their market risk is subject to the impact of the S\&P 500 index return in US. The daily data were downloaded from data stream. Equity index risk during the subprime crisis is analyzed based on the methodology outlined above. Daily returns are calculated as

$$
r_{t}=100 \times\left(\ln \left(p_{t}\right)-\ln \left(p_{t-1}\right)\right) .
$$

In addition, because the US market opens later than the other countries, in order to analyze the impact of S\&P 500 index returns on the tested markets, we use the returns on day $t-1$ for the S\&P 500 index and the returns on day $t$ for the tested markets when calculating Kendall tau and Pearson correlation coefficients. Meanwhile, it should be noted that 
TABLE 1: Summary statistics of log daily index returns. This table provides summary statistics of log daily index returns for six markets, including the US (S\&P 500 index), China (CSI 300 index), Japan (Nikkei 225 index), UK (FTSE-100 index), France (CAC-40 index), and Germany (DAX index) from June 1, 2006, to July 25, 2013. The Kendall tau correlation coefficient $\left(\rho_{\tau}\right)$ and Pearson correlation coefficient $(\rho)$ between the US and tested countries are also reported.

\begin{tabular}{lcccccc}
\hline & US & China & Japan & UK & France & Germany \\
\hline Mean & 0.01 & 0.0345 & 0.01 & 0.0129 & $-9 e-04$ & 0.0288 \\
Median & 0.0808 & 0.1176 & 0.048 & 0.0469 & 0.0297 & -1026 \\
Min & -9.4695 & -9.6952 & -12.111 & -9.2656 & -7.335 \\
Max & 10.9572 & 8.9309 & 13.2346 & 9.3843 & 10.5946 & 1.5349 \\
Stdev & 1.3736 & 1.8993 & 1.6547 & 1.2979 & -0.7975 \\
Skewness & -0.1751 & -0.3594 & -0.581 & 7.6485 & 0.1327 & 6.1511 \\
Kurtosis & 9.5992 & 2.7969 & 8.3085 & 0 & 0.4629 \\
KS $(P$ value $)$ & 0 & 0 & 0 & 0.1206 & 0.1375 \\
$\rho_{\tau}$ & & 0.0873 & 0.3317 & 0.2542 & 0.3971 \\
$\rho$ & & 0.1476 & 0.5223 & & 0.2354 & 0.1125 \\
\hline
\end{tabular}

Note: the overall sample period is from 1/2006 to 7/2013. Standard errors are in parentheses.

if one of the markets has a holiday, that is, when it is closed for any trading day other than the weekend, we delete the observations $t-1$ for the other markets. Hence, each of the two markets between American market and markets of tested countries has exactly the same trading days.

Summary statistics of the index returns are reported in Table 1. We find that all returns except for France and Germany are negatively skewed and the excess kurtosis of all returns is larger than zero. In terms of the KolmogorovSmirnov test, all the distribution of the series of six returns deviates from normal distribution. Returns from all six indices exhibit the characteristics of high kurtosis and fat tail. Table 1 also reports the Kendall correlation coefficient, $\rho_{\tau}$, and Pearson correlation coefficient, $\rho$, between return of the S\&P 500 index and lagged returns from the tested stock markets. We observed a relatively loose Kendall tau correlation coefficient between the US and China stock markets (0.0873), but tighter correlation between the US and Japan (0.3317), UK (0.1206), France (0.1086), and Germany (0.1125). Pearson correlation coefficient presents the same pattern as Kendall tau correlation coefficient. Perhaps because stock market in China is weak from efficiency and highly regulated, changes in market value of listed companies are difficult to react to those in their intrinsic value quickly and accurately.

Figure 1 illustrates the evolution of stock market returns over time. The figure indicates that all markets have trembled since 2008. Stock markets show volatility clustering, revealing the presence of heteroscedasticity. This characteristic supports the usefulness of dynamic conditional autoregressive model to analyze dynamic character in stock returns. Meanwhile, due to the effect of European debt crisis, there are high volatilities around 2011. However, there is no obvious evidence that high volatilities appear in Chinese and Japanese stock returns in Figure 1 around the period. It may be due to the little impact of the European debt crisis on China and Japan.

4.2. Model Specification. To provide evidence of the volatility clustering phenomenon in financial time series and financial contagion from the American subprime crisis to market indices of the tested countries, the MV-CAViaR models are estimated as a function of one lagged quantiles and one lagged returns of other countries. Next, we estimate the following system of equations for the conditional quantiles of the US and one of the tested countries (i.e., China, Japan, UK, France, and Germany). Consider

$$
\begin{aligned}
& q_{1, t}=c_{1}+a_{12}\left|Y_{2, t-1}\right|+b_{11} q_{1, t-1}, \\
& q_{2, t}=c_{2}+a_{21}\left|Y_{1, t-1}\right|+b_{22} q_{2, t-1},
\end{aligned}
$$

where $Y_{1, t-1}, Y_{2, t-1}$ are separately denoted as the daily return on one of the indices of the tested countries and that on the index of America at time $t-1 . q_{1, t}, q_{2, t}$ represent $5 \%$ quantiles of one of the returns on the indices of tested countries and American stock index return at time $t$, respectively. In the framework of the specified model (10), $b_{11}, b_{22}$ can be used to test whether there are the characteristics of volatility clustering in the responding stock markets. If $b_{11}, b_{22}$ are significantly different from zero at some given significance level, it indicates that there is volatility clustering phenomenon in the responding stock markets. Similar to the discussion above, the coefficients $a_{12}, a_{21}$ can be used to capture financial contagion. If $a_{12}$ is significantly different from zero, it shows that there is financial contagion from America to the tested countries. Similarly, if $a_{21}$ is significantly different from zero, it indicates that there is risk spillover from equity markets of the tested countries to American equity market. Thus, we call $a_{12}, a_{21}$ contagious coefficients. Meanwhile, contagious coefficients can be used to analyze the variation of market risk. From the model (10), we can see that the smaller the contagious coefficients are, the larger the risks in stock market of the infected countries are. Furthermore, the negative contagious coefficients imply that the market risks in the infected countries increase.

In addition, estimating the system of (10) is not trivial. We perform the computations in a step-wise fashion as follows. 


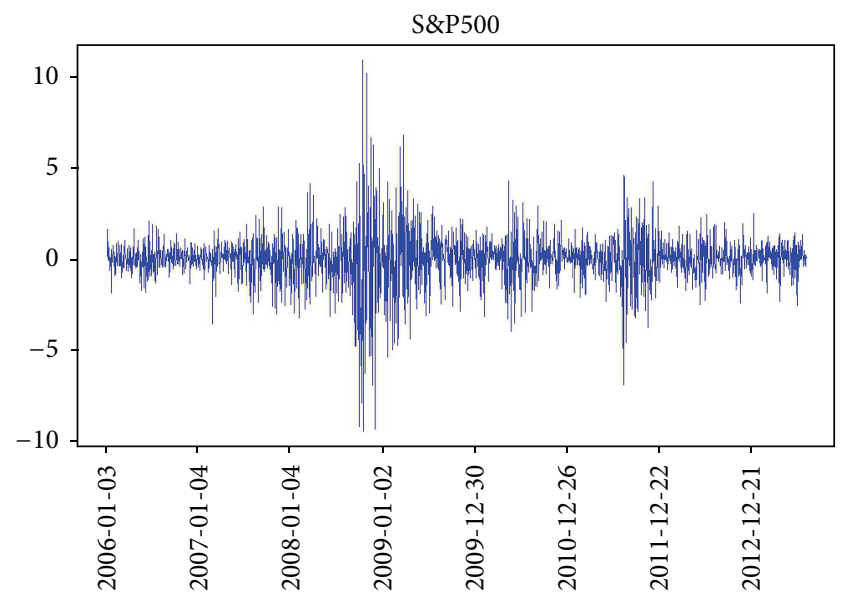

(a)

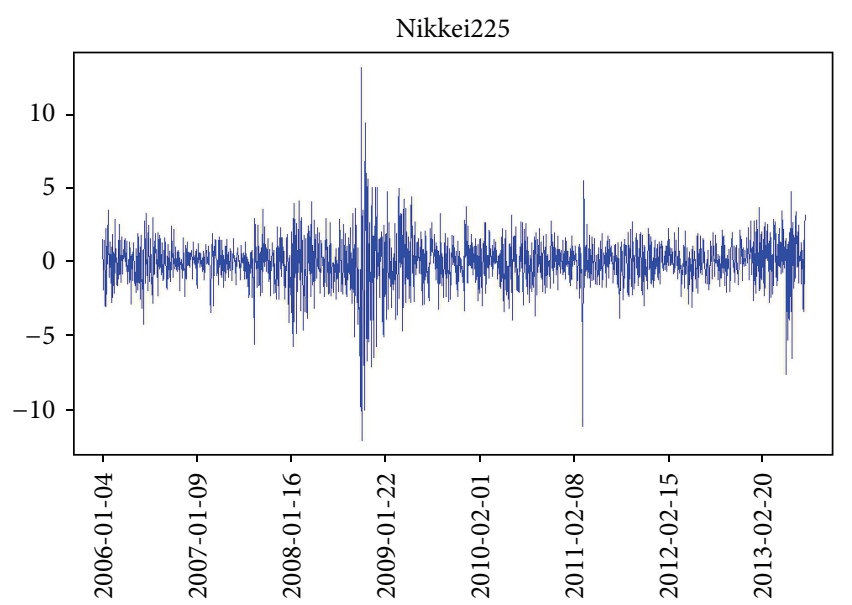

(c)

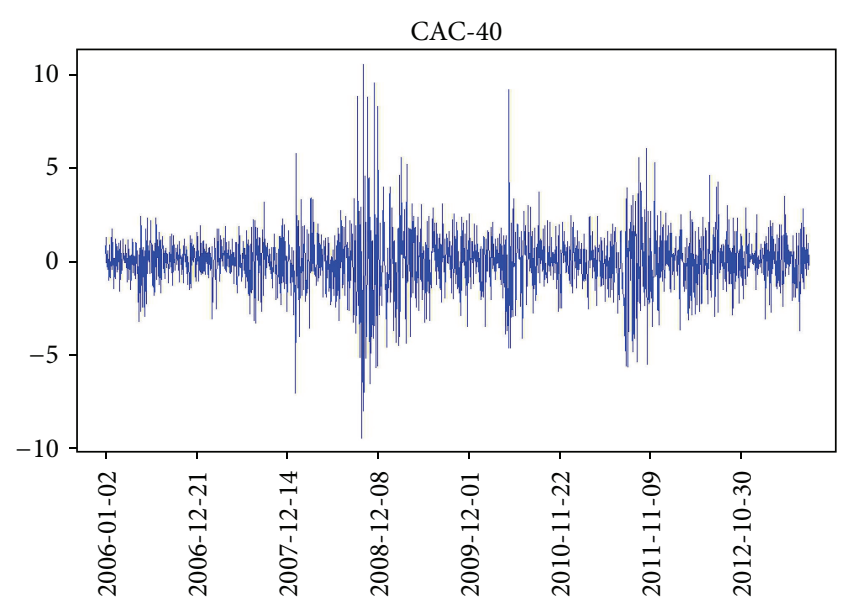

(e)

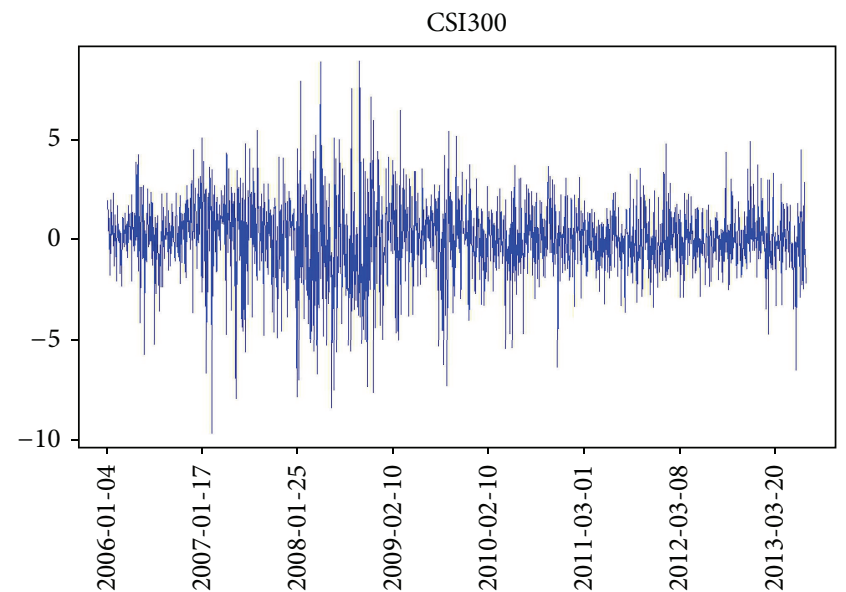

(b)

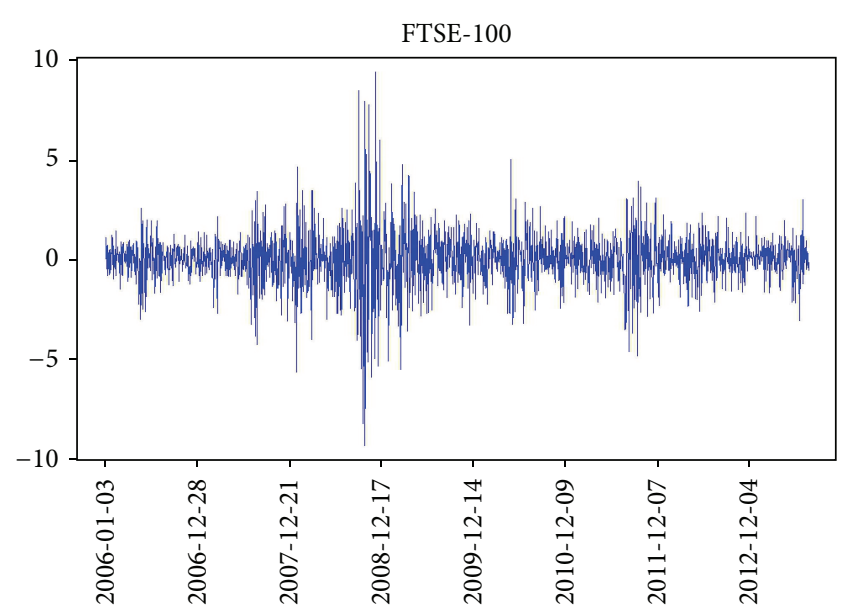

(d)

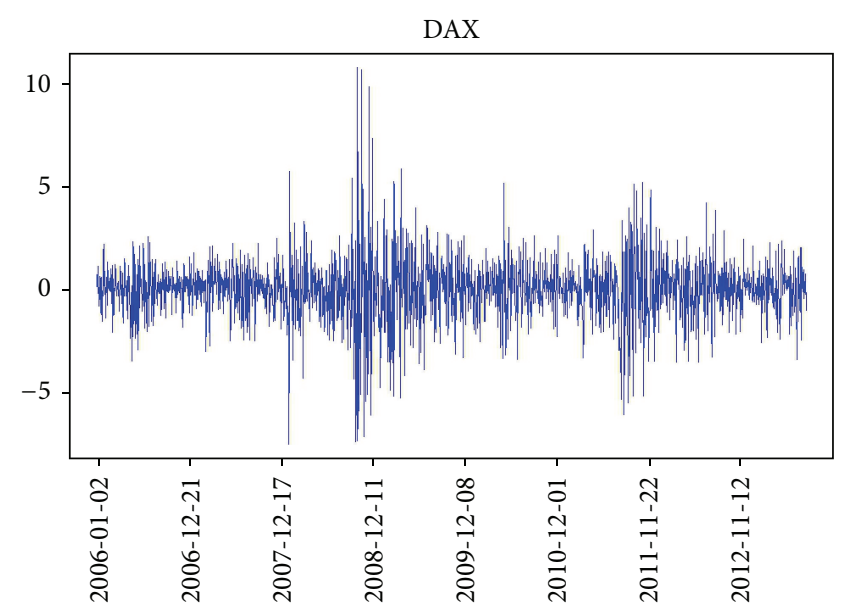

(f)

FIGURE 1: Daily returns of S\&P500 (US), CSI300 (China), Nikkei225 (Japan), FTSE-100 (UK), CAC-40 (France), and DAX (Germany). Notes: daily data from January 2006 to July 2013. 
TABLE 2: Estimates of MV-CAViaR model for the overall sample.

\begin{tabular}{lcccccc}
\hline Parameters & $c_{1}$ & $a_{12}$ & $b_{11}$ & $c_{2}$ & $a_{21}$ & $b_{22}$ \\
\hline \multirow{2}{*}{ US/China } & -0.0350 & -0.0157 & 0.9852 & 0.0034 & -0.0116 & 0.9942 \\
& $(0.0107)^{* * *}$ & $(0.0047)^{* * *}$ & $(0.0041)^{* * *}$ & $(0.0015)^{* *}$ & $(0.0016)$ & $(0.0007)^{* * *}$ \\
\hline \multirow{2}{*}{ US/Japan } & -0.7877 & -1.0917 & 0.3103 & -0.0039 & 0.0089 & 1.0045 \\
& $(0.1674)^{* * *}$ & $(0.0853)^{* * *}$ & $(0.0679)^{* * *}$ & $(0.0013)^{* * *}$ & $(0.0025)^{* * *}$ & $(0.0009)^{* * *}$ \\
\hline \multirow{2}{*}{ US/Australia } & -0.4195 & -0.6613 & 0.4356 & -0.7129 & -1.2766 & 0.2390 \\
& $(0.0740)^{* * *}$ & $(0.0769)^{* * *}$ & $(0.0575)^{* * *}$ & $(0.1552)^{* *}$ & $(0.0862)^{* * *}$ & $(0.0758)^{* * *}$ \\
\hline \multirow{2}{*}{ US/UK } & -1.6514 & -0.3998 & 0.0293 & 0.0357 & -0.3188 & 0.8806 \\
& $(0.3451)^{* * *}$ & $(0.1074)^{* * *}$ & $(0.1702)^{* * *}$ & $(0.0173)^{* *}$ & $(0.0431)^{* * *}$ & $(0.0140)^{* * *}$ \\
\hline \multirow{2}{*}{ US/France } & -0.2077 & -0.3289 & 0.79422 & -1.6113 & -0.5503 & 0.0132 \\
& $(0.0466)^{* * *}$ & $(0.0626)^{* * *}$ & $(0.0368)^{* * *}$ & $(0.2641)^{* * *}$ & $(0.1143)^{* * *}$ & $(0.1151)$ \\
\hline \multirow{2}{*}{ US/Germany } & -0.1907 & -0.2937 & 0.8031 & -0.0022 & -0.2847 & 0.8669 \\
& $(0.0476)^{* * *}$ & $(0.0608)^{* * *}$ & $(0.0384)^{* * *}$ & $(0.0223)$ & $(0.0574)^{* * *}$ & $(0.0224)^{* * *}$ \\
\hline
\end{tabular}

Note: the overall sample period is from $1 / 2006$ to $7 / 2013$. Standard errors are in parentheses.

** Significant at $5 \%$ level.

${ }^{* * *}$ Significant at $1 \%$ level.

Step 1. We use the QMLE method to estimate single CAViaR models: $q_{1, t}=c_{1}+b_{11} q_{1, t-1}$ and $q_{2, t}=c_{2}+b_{22} q_{2, t-1}$, respectively, with the initial value of $c_{i}(i=1,2)$ equal to the responding $\theta$ th sample quantiles of $Y_{i}(i=1,2)$. We initialize the remaining parameters at zero.

Step 2. We use the parameter estimates of step 1 as the starting values for the optimization of the CAViaR models: $q_{1, t}=c_{1}+$ $a_{12}\left|Y_{2, t-1}\right|+b_{11} q_{1, t-1}$ and $q_{2, t}=c_{2}+a_{21}\left|Y_{1, t-1}\right|+b_{22} q_{2, t-1}$, setting to zero the remaining parameters.

Step 3. We use the estimates from step 2 as the starting values for the full MV-CAViaR model (10) optimization, which contains two financial institutions of interest simultaneously.

4.3. Whole Sample Analysis. To capture the changes of market risk throughout the sampling period, we estimate the system of (10) for the entire sampling period. Table 2 displays the results of the model specified in (10) for tested countries and America.

Table 2 shows that the coefficients, $b_{11}$ and $b_{22}$, are positive in each case and almost significant. It indicates that risk of stock markets is positive autocorrelation. In other words, there is volatility clustering phenomenon in stock markets. This is consistent with the conclusions of the existing research literatures, for example, Teyssiere and Kirman [51], Niu and Wang [52], and so on. Meanwhile, the contagious coefficients significantly deviate from zero in each case and are negative except for Japan. It implies that there may be financial contagion between the US and the tested countries and one country's risk increases due to another country except for Japan. It is interesting to find that the magnitude of the contagious coefficients is the smallest for China among all the examined countries. The parameter estimates of $a_{12}$ and $a_{21}$ are only -0.0157 and -0.0116 , respectively. This means that the degree of risk spillovers for China is smallest and America has a lighter effect on China than the other investigated countries. It is consistent with the results in Table 1 that there is the smallest Kendall tau correlation coefficient between China and America.

Figure 2 illustrates the evolution of the estimated VaR at the level of $5 \%$ under the structure of the system of (10) from January 2006 to July 2013. The figure exhibits that all markets are subjected to high risks since 2008. Stock markets show the characteristics of high risk during the period of the financial crisis of 2008-2009.

However, it should be noted that estimated sampling period includes the crisis period and noncrisis period. Thus, we cannot distinguish whether the contagion is caused by the financial crisis originating from American subprime crisis. In order to overcome the defect, we consider the estimations for three important subsamples in the structure of model (10). The first runs from January 2006 to December 2007 which we refer to as the precrisis period. The second starts at the beginning of 2008, right after NBER identified December of 2007 as the start of the major recent financial crisis in the US. The US recession officially ended in June 2009, although economic growth has since been sluggish. The third subsample from July 2009 to July 2013 refers to the US economy entering a recovery phase.

4.4. Financial Contagion Analysis. As discussed in the previous section, there exists financial contagion from the US stock market to the foreign stock markets if one of the two following conditions is satisfied. (i) The contagious coefficient, $a_{12}$, is insignificant during the precrisis period, but it is significant during the crisis. (ii) If the contagious coefficient, $a_{12}$, is significant during both the precrisis and crisis period, but compared to the contagious coefficient, $a_{12}$, during the precrisis period, the estimated coefficient, $a_{12}$, during the crisis becomes smaller, which implies that there is risk increase due to America during the crisis. From the two aspects, we analyze whether there is financial contagion from one country to another. The detailed results are shown in Tables 3-7. 


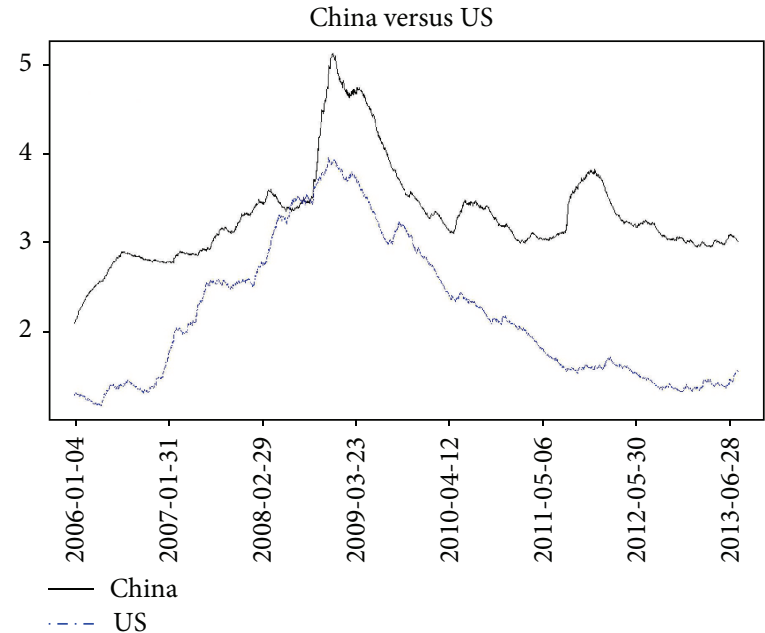

(a)

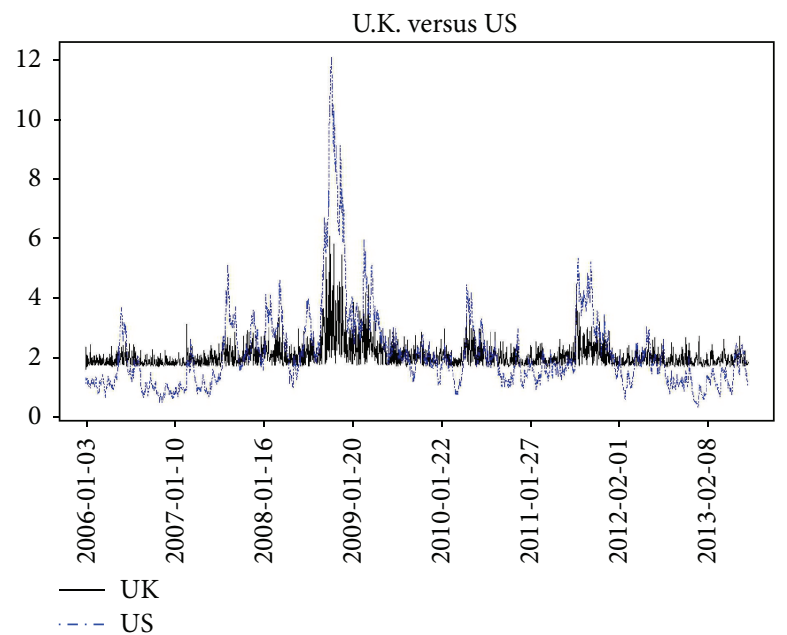

(c)

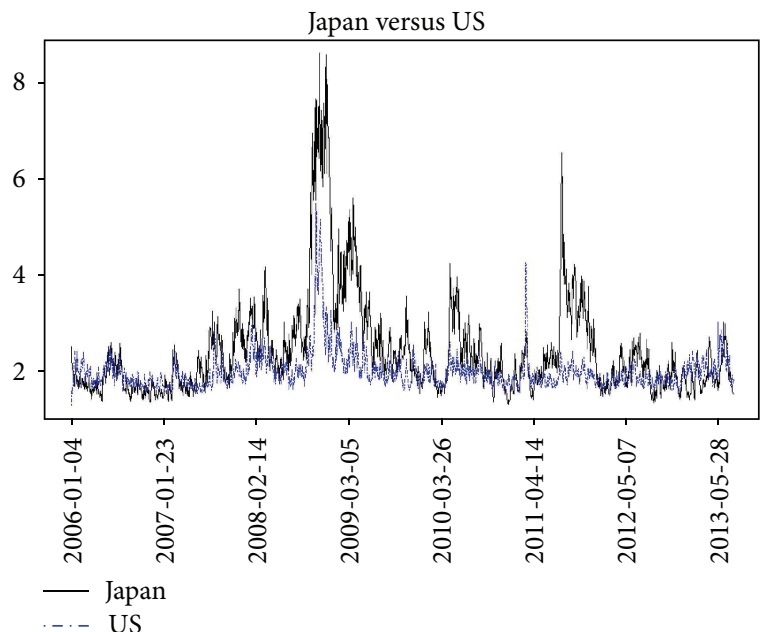

(b)

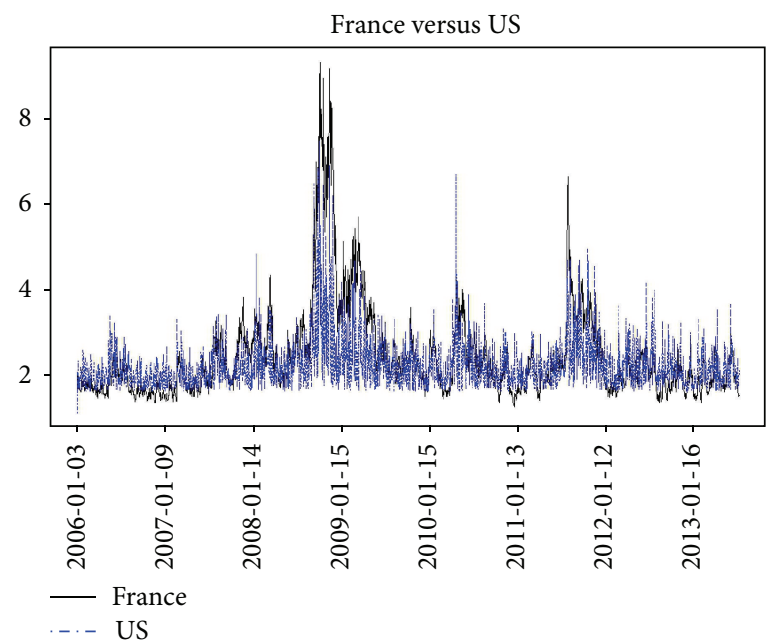

(d)

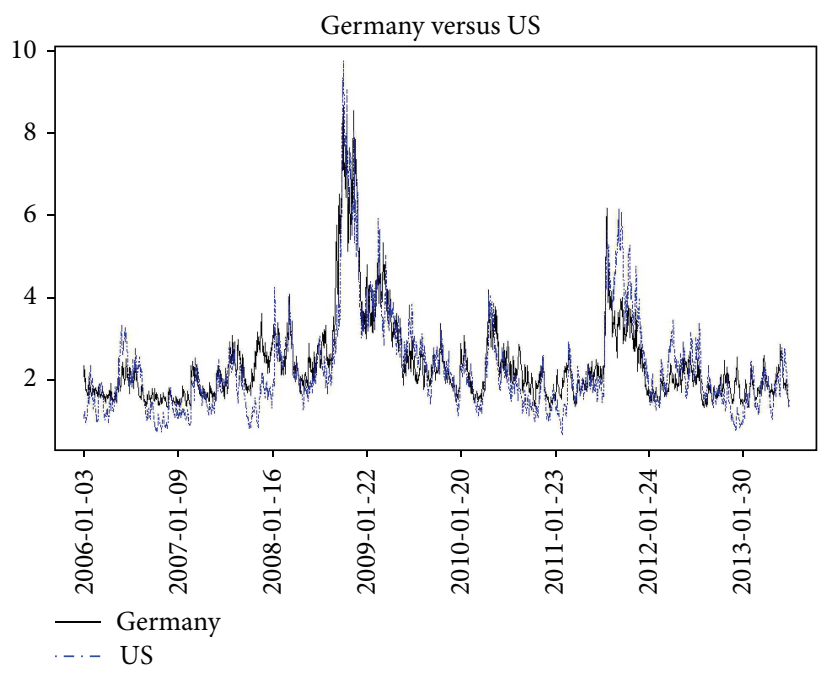

(e)

FIGURE 2: Estimated VaR at the level of $5 \%$ by the systems of (3). Notes: the overall sample period is from 1/2006 to 7/2013. 
TABLE 3: Financial contagion analysis between the US and China.

\begin{tabular}{lcccccc}
\hline Parameters & $c_{1}$ & $a_{12}$ & $b_{11}$ & $c_{2}$ & $a_{21}$ & $b_{22}$ \\
\hline \multirow{2}{*}{ Precrisis } & -0.0298 & 0.0580 & 1.0016 & 0.0166 & -0.0015 & 1.0118 \\
& $(0.0078)^{* * *}$ & $(0.0193)^{* * *}$ & $(0.0019)^{* * *}$ & $(0.0046)^{* * *}$ & $(0.0032)$ & $(0.0053)$ \\
\hline \multirow{2}{*}{ Crisis } & -0.5988 & 0.0294 & 0.8932 & 0.1006 & -0.0537 & 0.9954 \\
& $(1.4327)$ & $(0.0719)$ & $(0.2574)^{* * *}$ & $(0.0425)^{* * *}$ & $(0.0151)^{* * *}$ & $(0.0032)^{* * *}$ \\
\hline \multirow{2}{*}{ Recovery } & -4.8570 & 0.0554 & -0.8753 & -3.0359 & -0.0569 & -0.7033 \\
& $(0.1735)^{* * *}$ & $(0.0671)$ & $(0.0360)^{* * *}$ & $(0.7243)^{* * *}$ & $(0.0600)$ & $(0.3949)^{*}$ \\
\hline
\end{tabular}

Notes: standard errors are in parentheses. The overall sample period is portioned into three subsamples: a precrisis period spanning from 1/2006 to $12 / 2007$, a crisis period spanning from 1/2008 to 6/2009, and a recovery period spanning from 7/2009 to 7/2013

* Significant at $10 \%$ level.

*** Significant at $1 \%$ level.

TABLE 4: Financial contagion analysis between the US and Japan.

\begin{tabular}{lcccccc}
\hline Parameters & $c_{1}$ & $a_{12}$ & $b_{11}$ & $c_{2}$ & $a_{21}$ & $b_{22}$ \\
\hline \multirow{2}{*}{ Precrisis } & -3.5184 & -0.0866 & -0.7231 & -0.1383 & -0.0239 & 0.8897 \\
& $(1.2479)^{* * *}$ & $(0.1806)$ & $(0.6273)$ & $(0.4116)$ & $(0.0557)$ & $(0.3054)^{* * *}$ \\
\hline \multirow{2}{*}{ Crisis } & -0.9344 & -1.0917 & 0.3553 & -0.0333 & 0.0011 & 0.9949 \\
& $(0.2990)$ & $(0.0956)^{* * *}$ & $(0.0872)^{* * *}$ & $(0.0059)^{* * *}$ & $(0.0094)$ & $(0.0042)^{* * *}$ \\
\hline \multirow{2}{*}{ Recovery } & -2.7990 & 0.3103 & -0.3753 & 0.0161 & -0.0146 & 1.0001 \\
& $(1.3049)^{* *}$ & $(0.1331)$ & $(0.6186)$ & $(0.0047)^{* * *}$ & $(0.0049)^{* * *}$ & $(0.0010)^{* * *}$ \\
\hline
\end{tabular}

Notes: standard errors are in parentheses. The overall sample period is portioned into three subsamples: a precrisis period spanning from 1/2006 to 12/2007, a crisis period spanning from $1 / 2008$ to $6 / 2009$, and a recovery period spanning from $7 / 2009$ to $7 / 2013$.

${ }^{* *}$ Significant at $5 \%$ level.

${ }^{* * *}$ Significant at $1 \%$ level.

TABLE 5: Financial contagion analysis between the US and UK.

\begin{tabular}{lcccccc}
\hline Parameters & $c_{1}$ & $a_{12}$ & $b_{11}$ & $c_{2}$ & $a_{21}$ & $b_{22}$ \\
\hline \multirow{2}{*}{ Precrisis } & 0.0270 & 0.0292 & 1.0255 & 0.0171 & 0.0110 & 1.0208 \\
& $(0.0208)$ & $(0.0366)$ & $(0.0227)^{* * *}$ & $(0.0070)^{* *}$ & $(0.0169)$ & $(0.0107)^{* * *}$ \\
\hline \multirow{2}{*}{ Crisis } & 0.0148 & 0.0516 & 1.0291 & 0.0254 & -0.0516 & 0.9888 \\
& $(0.0089)^{*}$ & $(0.0128)^{* * *}$ & $(0.0038)^{* * *}$ & $(0.0109)^{* *}$ & $(0.0171)^{* * *}$ & $(0.0046)^{* * *}$ \\
\hline \multirow{2}{*}{ Recovery } & -3.4809 & -0.0129 & -0.9977 & -3.4290 & 0.0071 & -0.8669 \\
& $(0.0969)^{* * *}$ & $(0.0150)$ & $(0.0035)^{* * *}$ & $(0.7464)^{* * *}$ & $(0.0550)$ & $(0.4042)^{* * *}$ \\
\hline
\end{tabular}

Notes: standard errors are in parentheses. The overall sample period is portioned into three subsamples: a precrisis period spanning from 1/2006 to $12 / 2007$, a crisis period spanning from $1 / 2008$ to $6 / 2009$, and a recovery period spanning from 7/2009 to 7/2013.

${ }^{*}$ Significant at $10 \%$ level.

** Significant at $5 \%$ level.

*** Significant at $1 \%$ level.

TABLE 6: Financial contagion analysis between US and France.

\begin{tabular}{lcccccc}
\hline Parameters & $c_{1}$ & $a_{12}$ & $b_{11}$ & $c_{2}$ & $a_{21}$ & $b_{22}$ \\
\hline \multirow{2}{*}{ Precrisis } & -3.0343 & 0.0071 & -0.9769 & 0.0766 & 0.0000 & 1.0678 \\
& $(0.2408)^{* * *}$ & $(0.0399)$ & $(0.0859)^{* * *}$ & $(0.0000)^{* * *}$ & $(0.0000)$ & $(0.0000)^{* * *}$ \\
\hline \multirow{2}{*}{ Crisis } & -0.2327 & -0.4096 & 0.7474 & 0.0254 & -0.0664 & 0.9751 \\
& $(0.0782)^{* * *}$ & $(0.0954)^{* * *}$ & $(0.0500)^{* * *}$ & $(0.0122)$ & $(0.0196)^{* * *}$ & $(0.0065)^{* * *}$ \\
\hline \multirow{2}{*}{ Recovery } & -0.1490 & -0.2760 & 0.8462 & -3.4290 & 0.2311 & -0.5932 \\
& $(0.0693)^{* *}$ & $(0.1155)^{* *}$ & $(0.0583)^{* * *}$ & $(0.3309)^{* * *}$ & $(0.0990)^{* *}$ & $(0.1592)^{* * *}$ \\
\hline
\end{tabular}

Notes: standard errors are in parentheses. The overall sample period is portioned into three subsamples: a precrisis period spanning from $1 / 2006$ to $12 / 2007$, a crisis period spanning from $1 / 2008$ to $6 / 2009$, and a recovery period spanning from $7 / 2009$ to $7 / 2013$.

${ }^{* *}$ Significant at $5 \%$ level.

${ }^{* * *}$ Significant at $1 \%$ level. 
TABLE 7: Financial contagion analysis between the US and Germany.

\begin{tabular}{lcccccc}
\hline Parameters & $c_{1}$ & $a_{12}$ & $b_{11}$ & $c_{2}$ & $a_{21}$ & $b_{22}$ \\
\hline \multirow{2}{*}{ Precrisis } & -3.2792 & 0.0204 & -0.9912 & 0.0126 & 0.0019 & 1.0125 \\
& $(0.1669)^{* * *}$ & $(0.0152$ & $(0.0111)^{* * *}$ & $(0.0070)^{*}$ & $(0.0077)$ & $(0.0026)^{* * *}$ \\
\hline \multirow{2}{*}{ Crisis } & -0.0550 & -0.1400 & 0.9218 & -0.0044 & 0.0863 & 1.0386 \\
& $(0.0336)^{*}$ & $(0.0477)^{* * *}$ & $(0.0266)^{* * *}$ & $(0.0162)$ & $(0.0256)^{* * *}$ & $(0.0077)^{* * *}$ \\
\hline \multirow{2}{*}{ Recovery } & -4.3511 & 0.0133 & -0.8860 & -1.4618 & -0.4146 & 0.0097 \\
& $(1.3772)^{* * *}$ & $(0.0846)$ & $(0.6013)$ & $(0.4062)^{* * *}$ & $(0.1496)^{* * *}$ & $(0.2052)$ \\
\hline
\end{tabular}

Notes: standard errors are in parentheses. The overall sample period is portioned into three subsamples: a precrisis period spanning from 1/2006 to $12 / 2007$, a crisis period spanning from 1/2008 to 6/2009, and a recovery period spanning from 7/2009 to 7/2013.

* Significant at $10 \%$ level.

${ }^{* * *}$ Significant at $1 \%$ level.

In Table 3, we report the results between the US and China for the three subsample periods (precrisis period, crisis period, and recovery period). The result indicates that, compared to the precrisis period, there is no evidence that there is contagion from America to China. This is consistent with the fact that the impact of the subprime crisis on China is relatively small. In reality, the Chinese government had maintained a relatively calm attitude and did not show panic that appeared in other developed countries throughout the process, which, to a large extent, relieved the negative factors brought by the stagnant international financial market. But, to some extent, Chinese market has a relationship with American market due to the economic globalization. The reason why there is only one significant contagious coefficient $a_{21}$ during the crisis is that the linkage between the two markets increased during the crisis. Moreover, it should be noted that $a_{21}$ is negative. This is consistent with the fact that the market risk in America increased during the crisis. As is known to all, the risk increase in America is caused by its own market conditions of the day. During the recovery period, the contagious coefficients are insignificant, which suggests that there is weaker link and no significant effect during the period.

Table 4 summarizes the financial contagion analysis between American and Japanese stock markets. We find that, during the precrisis period, the contagious coefficients $a_{12}$ and $a_{21}$ are not statistically significant, but during the crisis $a_{12}$ is significant and $a_{21}$ is insignificant. This indicates that there is financial contagion from American equity market to Japanese equity market but no contagion from Japan to America. It should be noted that during the recovery period $a_{21}$ is the only significant contagious coefficient. This suggests that there may be contagion effect from Japanese equity market to American equity market during the recovery period. In fact, America is the second largest country for Japan and Japanese economy is affected by American economy. After the crisis, there is a strong economic resurgence in the US. However, in recent years, because the demand inside Japan is low and confused, economy is long-term backwater. As a result, American economy recovery is cumbered by Japanese sluggish economy. The significance of $a_{21}$ cannot be explained from the perspective of financial contagion. It should be explained from the standpoint that Japan has a negative effect on American economic recovery and increases the recovery risk of American economy.

The results in Table 5 reveal the contagion effects between the US and UK. The contagion coefficients are statistically significant at the level of $1 \%$ only during the crisis. It means that there is strong financial contagion from the US to UK during the financial crisis. It is obvious that the comovements between the US and UK become stronger in contrast with noncrisis period. It is possible that there are strong historical ties between the two countries. British corporations are one of the largest foreign investors in the US. The tighter relations between the two countries may lead to the significant contagion coefficient $a_{21}$ during the period of crisis. At last, the insignificance of the contagion coefficients suggests that the relations between the countries return to the state of the precrisis.

Table 6 shows the contagion test results between the US and France. There is strong evidence of spillover risks between the US and French markets. The contagious coefficients are statistically significant at the level of $1 \%$ during the crisis period. Moreover, they are negative and the contagious coefficient $a_{12}$ from America to France is -0.4096 , and contagious coefficient $a_{21}$ from France to America is -0.0664 . Because the financial crisis of 2008-2009 is caused by American subprime crisis, we only say that there is financial contagion from America to France. In other words, the existence of the financial contagion from the US to France leads to a stronger linkage between the two countries. In addition, from the magnitude of contagion coefficients, America has a stronger effect on France, which is consistent with the fact that the financial crisis is originating from America. At last, in comparison with the crisis period, the contagion coefficients are significant at level of $5 \%$ but larger. It means that the comovements between the two countries become weaker and risk spillovers become smaller during the recovery period. The global economy steps in a recovery phase.

In Table 7, we present estimated model parameters for the US and Germany. Estimates of the contagious coefficients, $a_{12}$ and $a_{21}$, show that there is evidence of financial contagion between the US and Germany. Furthermore, in terms of the sign of the contagious coefficients, we see clearly that America increases stock market risk in Germany and Germany decreases the risk in American stock market. Similar to 
the discussion above, we say that the direction of contagion is from America to Germany and there exists a stronger linkage between the US and Germany. During the recovery period, only one contagion coefficient, $a_{21}$, is significant. Furthermore, the sign of it is negative, which implies that Germany increases the market risk in America during the period. That is to say, Germany becomes a burden on the recovery of American economy. It is possible that European debt crisis has more serious effect on German economy than on American economy and the recovery speed of American economy is faster than that of German economy.

\section{Conclusions}

In this paper, we examine whether the subprime crisis originating from the US led to risk spillovers in financial indices in major mature markets (Japan, UK, France, Germany) and one of the largest emerging markets (China). We apply the MVCAViaR model to the whole sample period from 1 January 2006 to 25 July 2013. The findings show that there is a significant increase in market risk during the crisis. To investigate the changes of dependence structure during the crisis and noncrisis period, we divide the sampling period into three important subperiods: precrisis period, crisis period, and recovery period according to the announcements by NBER and government.

The piecewise estimated results show that American subprime crisis spilled over to Japan, UK, France, and Germany and increased their market risks during the crisis in comparison with the turmoil period. But, we have not found statistically significant evidence showing that there is financial contagion from America to China. During the recovery period, the strong linkages between the US and France still exist, but there is a simultaneous decrease in the market risks of both countries. As for UK, there is no contagion during the recovery period. But, it should be noted that there are spillover risks from Japan and Germany to the US due to market conditions of the day.

The findings of our paper contribute to the ongoing debate on the detection, modeling, and especially risk analysis of financial contagion. It is of great significance for investors and portfolio managers to determine the existence of financial contagion as well as risk variation before and after financial crisis. In near future, it would be interesting research areas to study how the methodology could be applied to asset and risk management despite the existing contagion in some regions.

\section{Conflict of Interests}

The authors declare that there is no conflict of interests regarding the publication of this paper.

\section{Acknowledgments}

This research is supported by National Natural Science Foundation of China (nos. 71371007 and 71271199), Program for
New Century Excellent Talents in University (no. NCET-130538), and the Fundamental Research Funds for the Central Universities of China (no. WK2040160008).

\section{References}

[1] K. J. Forbes and R. Rigobon, "No contagion, only interdependence: measuring stock market comovements," Journal of Finance, vol. 57, no. 5, pp. 2223-2261, 2002.

[2] T. Baig and I. Goldfajn, "Financial market contagion in the Asian crisis," IMF Staff Papers, vol. 46, no. 2, pp. 167-195, 1999.

[3] K.-H. Bae, G. A. Karolyi, and R. M. Stulz, "A new approach to measuring financial contagion," Review of Financial Studies, vol. 16, no. 3, pp. 717-763, 2003.

[4] D. G. Baur, "The structure and degree of dependence: a quantile regression approach," Journal of Banking and Finance, vol. 37, no. 3, pp. 786-798, 2013.

[5] R. F. Engle and S. Manganelli, "CAViaR: conditional autoregressive value at risk by regression quantiles," Journal of Business \& Economic Statistics, vol. 22, no. 4, pp. 367-381, 2004.

[6] H. White, T. H. Kim, and S. Manganelli, "Modeling autoregressive conditional skewness and kurtosis with multi-quantile CAViaR," European Central Bank Working Paper Series 0957, 2008.

[7] H. White, T. H. Kim, and S. Manganelli, "VAR for VaR: measuring systemic risk using multivariate regression quantiles," MPRA Paper 35372, 2010.

[8] A. V. Mollick and T. A. Assefa, "U.S. stock returns and oil prices: the tale from daily data and the 2008-2009 financial crisis," Energy Economics, vol. 36, pp. 1-18, 2013.

[9] G. L. Kaminsky, C. M. Reinhart, and C. A. Végh, "The unholy trinity of financial contagion," Journal of Economic Perspectives, vol. 17, no. 4, pp. 51-74, 2003.

[10] A. V. Banerjee, "A simple model of herd behavior," The Quarterly Journal of Economics, vol. 107, no. 3, pp. 797-817, 1992.

[11] G. A. Calvo and E. G. Mendoza, "Macroeconomics of emerging markets: capital-markets crises and economic collapse in emerging markets: an informational-frictions approach," The American Economic Review, vol. 90, no. 2, pp. 59-64, 2000.

[12] A. Lahiri and C. A. Végh, "Delaying the inevitable: interest rate defense and balance of payments crises," Journal of Political Economy, vol. 111, no. 2, pp. 404-424, 2003.

[13] S. Gerlach and S. Frank, "Contagious speculative attacks," CEPR Discussion Paper 1055, 1996.

[14] L. E. Kodres and M. Pritsker, "A rational expectations model of financial contagion," Journal of Finance, vol. 57, no. 2, pp. 769799, 2002.

[15] M. Fratzscher, "On currency crises and contagion," International Journal of Finance and Economics, vol. 8, no. 2, pp. 109129, 2003.

[16] C. Reinhart and S. Calvo, "Capital flows of Latin America: is there evidence of contagion effects?” MPRA Paper 7124, 1996.

[17] M. D. Bordo and A. P. Murshid, "Are financial crises becoming increasingly more contagious? What is historical evidence on contagion?” NBER Working Paper 7900, 2000.

[18] K. Forbes and R. Rigobon, "Contagion in Latin America: definitions, measurement, and policy implications," NBER Working Papers 7885, 2000.

[19] G. Corsetti, M. Pericoli, and M. Sbracia, "Correlation analysis of financial contagion: what one should know before running a 
test," Yale University Economic Growth Center working paper 822, 2005.

[20] R. Rigobon, "On the measurement of the international propagation of shocks: is the transmission stable?" Journal of International Economics, vol. 61, no. 2, pp. 261-283, 2003.

[21] T. C. Chiang, B. N. Jeon, and H. Li, "Dynamic correlation analysis of financial contagion: evidence from Asian markets," Journal of International Money and Finance, vol. 26, no. 7, pp. 12061228, 2007.

[22] K. Naoui, S. Khemiri, and N. Liouane, "Crises and financial contagion: the subprime crisis," Journal of Business Studies Quaterly, vol. 2, no. 1, pp. 15-28, 2010.

[23] S. Celik, "The more contagion effect on emerging markets: the evidence of DCC-GARCH model," Economic Modelling, vol. 29, no. 5, pp. 1946-1959, 2012.

[24] D. Dimitriou, D. Kenourgios, and T. Simos, "Global financial crisis and emerging stock market contagion: a multivariate FIAPARCH-DCC approach," International Review of Financial Anal-ysis, vol. 30, pp. 46-56, 2013.

[25] T. Bollerslev, R. Y. Chou, and K. F. Kroner, "ARCH modeling in finance. A review of the theory and empirical evidence," Journal of Econometrics, vol. 52, no. 1-2, pp. 5-59, 1992.

[26] M. Billio and M. Caporin, "Market linkages, variance spillovers, and correlation stability: empirical evidence of financial contagion," Computational Statistics \& Data Analysis, vol. 54, no. 11, pp. 2443-2458, 2010.

[27] G. Bekaert and G. Wu, "Asymmetric volatility and risk in equity markets," Review of Financial Studies, vol. 13, no. 1, pp. 1-42, 2000.

[28] J. A. Chan-Lau, D. J. Mathieson, and J. Y. Yao, "Extreme contagion in equity markets," IMF Staff Papers, vol. 51, no. 2, pp. 386-408, 2004.

[29] P. Cumperayot, T. Keijzer, and R. Kouwenberg, "Linkages between extreme stock market and currency returns," Journal of International Money and Finance, vol. 25, no. 3, pp. 528-550, 2006.

[30] R. Gropp, M. Lo Duca, and J. Vesala, "Cross-border bank contagion in Europe," ECB Working Paper 662, 2006.

[31] B. H. Boyer, T. Kumagai, and K. Yuan, "How do crises spread? Evidence from accessible and inaccessible stock indices," Journal of Finance, vol. 61, no. 2, pp. 957-1003, 2006.

[32] G. M. Gallo and E. Otranto, "Volatility spillovers, interdependence and comovements: a Markov switching approach," Computational Statistics \& Data Analysis, vol. 52, no. 6, pp. 30113026, 2008.

[33] J. Chevallier, "Global imbalances, cross-market linkages, and the financial crisis: a multivariate Markov-switching analysis," Economic Modelling, vol. 29, no. 3, pp. 943-973, 2012.

[34] G. Corsetti, M. Pericoli, and M. Sbracia, "Some contagion, some interdependence': more pitfalls in tests of financial contagion," Journal of International Money and Finance, vol. 24, no. 8, pp. 1177-1199, 2005.

[35] P. Embrechts, F. Lidskog, and A. J. McNeal, "Modelling dependence with copulas and applications to risk management," in Handbook of Heavy Tailed Distributions in Finance, S. T. Rachev, Ed., pp. 329-384, Elsevier, North-Holland, The Netherlands, 2003.

[36] L. Hu, "Dependence patterns across financial markets: a mixed copula approach," Applied Financial Economics, vol. 16, no. 10, pp. 717-729, 2006.
[37] J. C. Rodriguez, "Measuring financial contagion: a Copula approach," Journal of Empirical Finance, vol. 14, no. 3, pp. 401423, 2007.

[38] S. Jayech and N. B. Zina, "A copula-based approach to financial contagion in the foreign exchange markets," International Journal of Mathematics in Operational Research, vol. 3, no. 6, pp. 636-657, 2011.

[39] W. Ye, X. Liu, and B. Miao, "Measuring the subprime crisis contagion: evidence of change point analysis of copula functions," European Journal of Operational Research, vol. 222, no. 1, pp. 96103, 2012.

[40] M. Gallegati, "A wavelet-based approach to test for financial market contagion," Computational Statistics \& Data Analysis, vol. 56, no. 11, pp. 3491-3497, 2012.

[41] S. Dajcman, M. Festic, and A. Kavkler, "Comovement dynamics between central and eastern European and developed European stock markets during European integration and amid financial crises-a wavelet analysis," Engineering Economics, vol. 23, no. 1, pp. 22-32, 2012.

[42] D. Baur and N. Schulze, "Coexceedances in financial marketsa quantile regression analysis of contagion," Emerging Markets Review, vol. 6, no. 1, pp. 21-43, 2005.

[43] C.-C. Chuang, C.-M. Kuan, and H.-Y. Lin, "Causality in quantiles and dynamic stock return-volume relations," Journal of Banking and Finance, vol. 33, no. 7, pp. 1351-1360, 2009.

[44] B. S. Lee and M.-Y. L. Li, "Diversification and risk-adjusted performance: a quantile regression approach," Journal of Banking and Finance, vol. 36, no. 7, pp. 2157-2173, 2012.

[45] K. Yu and J. Zhang, "A three-parameter asymmetric Laplace distribution and its extension," Communications in Statistics. Theory and Methods, vol. 34, no. 9-10, pp. 1867-1879, 2005.

[46] M. B. Stinchcombe and H. White, "Consistent specification testing with nuisance parameters present only under the alternative," Econometric Theory, vol. 14, no. 3, pp. 295-325, 1998.

[47] H. White, "Approximate nonlinear forecasting methods," in Handbook of Economic Forecastin, G. Elliott, C. W. J. Granger, and A. Timmermann, Eds., pp. 460-512, Elsevier, New York, NY, USA, 2006.

[48] K. Yu and R. A. Moyeed, "Bayesian quantile regression," Statistics \& Probability Letters, vol. 54, no. 4, pp. 437-447, 2001.

[49] R. Koenker and J. A. F. Machado, "Goodness of fit and related inference processes for quantile regression," Journal of the American Statistical Association, vol. 94, no. 448, pp. 1296-1310, 1999.

[50] R. Koenker and G. Bassett, Jr., "Regression quantiles," Econometrica, vol. 46, no. 1, pp. 33-50, 1978.

[51] G. Teyssiere and A. P. Kirman, Long Memory in Economics, Springer, Berlin, Germany, 2007.

[52] H. Niu and J. Wang, "Volatility clustering and long memory of financial time series and financial price model," Digital Signal Processing, vol. 23, no. 2, pp. 489-498, 2013. 


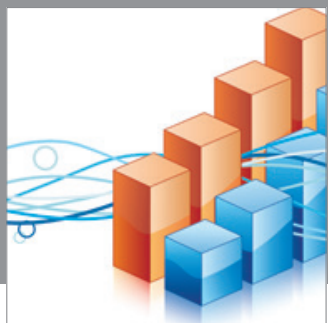

Advances in

Operations Research

mansans

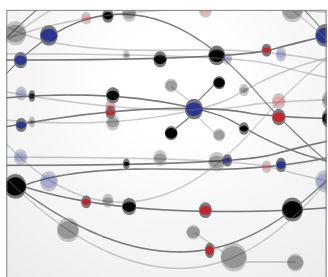

The Scientific World Journal
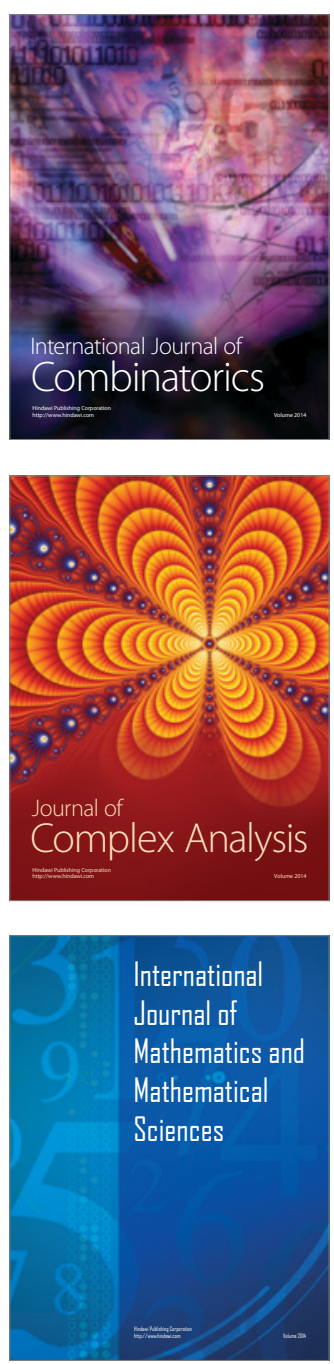
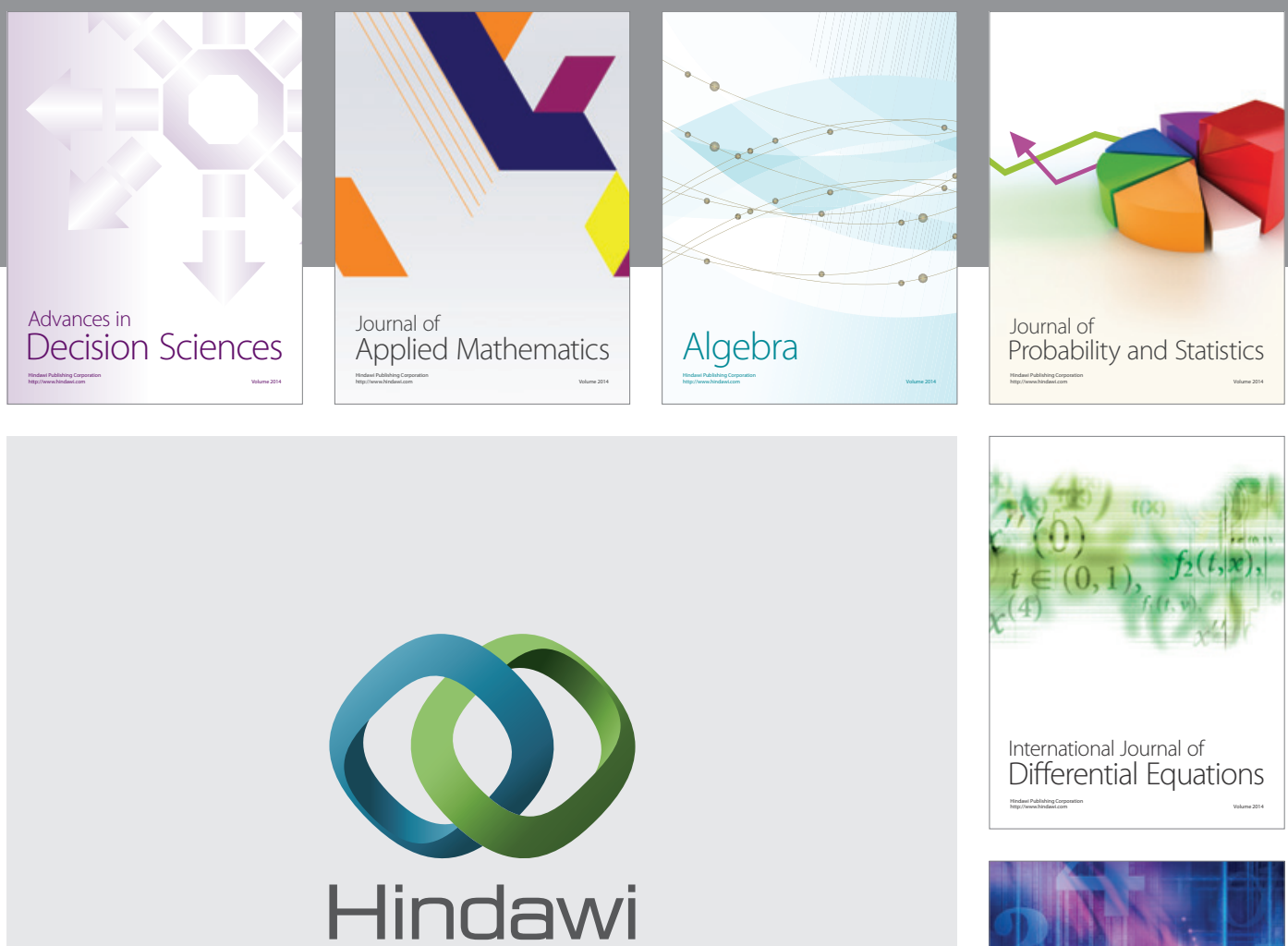

Submit your manuscripts at http://www.hindawi.com
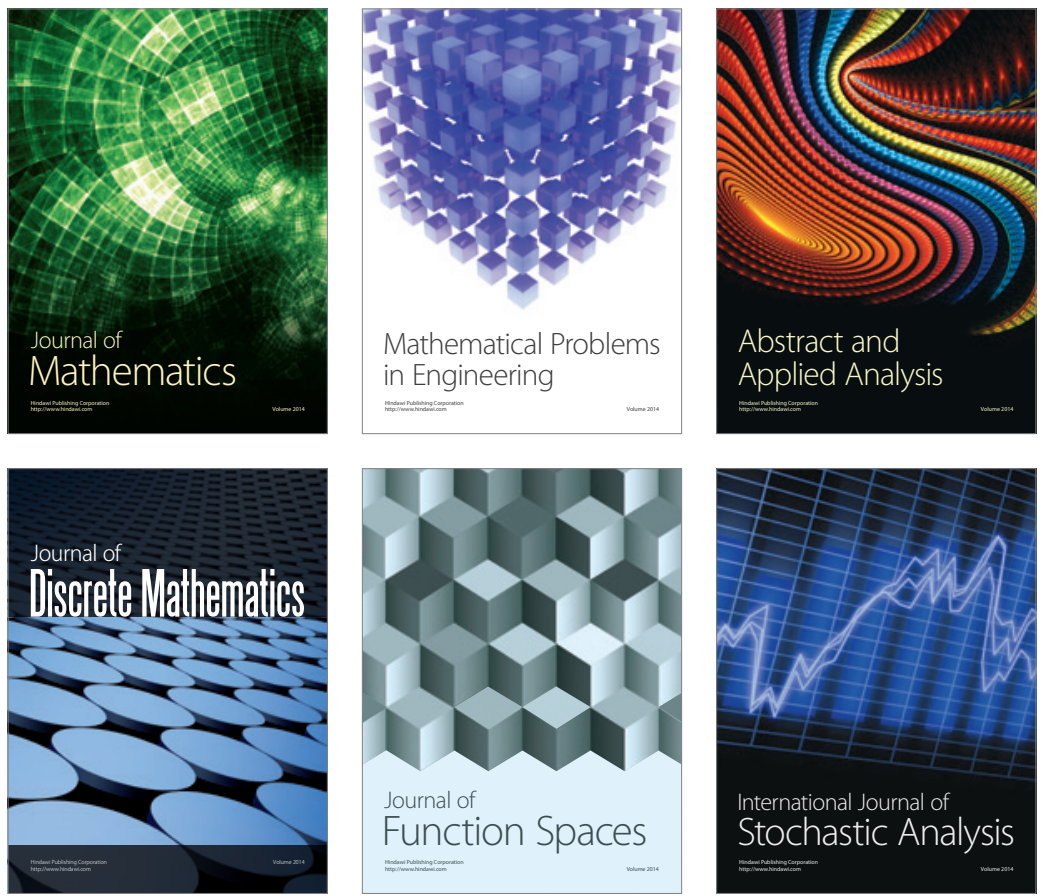

Journal of

Function Spaces

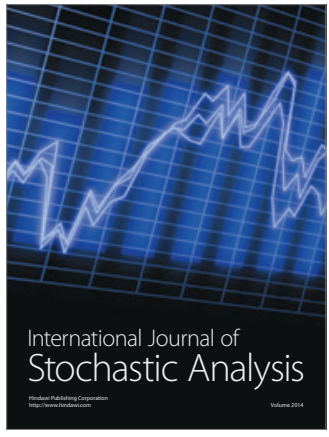

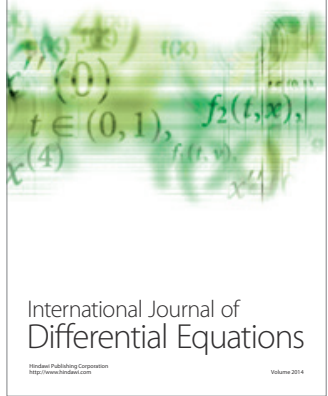
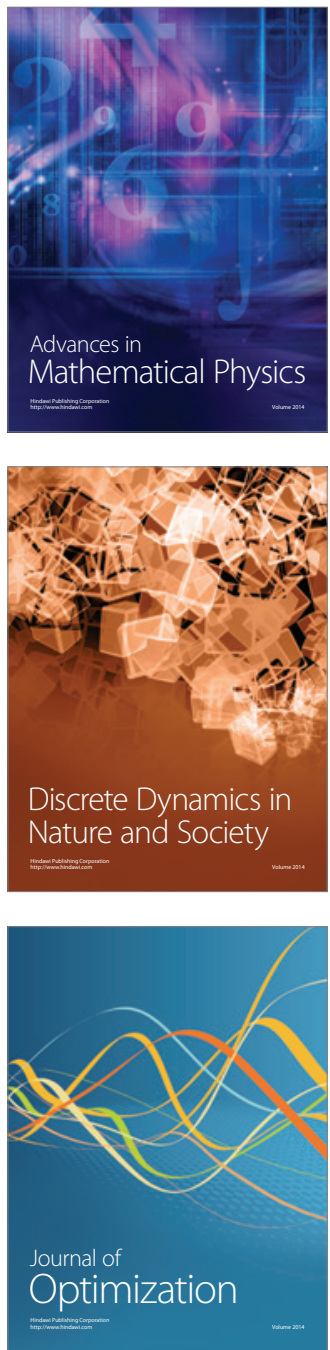